\title{
Retranslation hypotheses revisited: A case study of two English translations of Sanguo Yanyi - the first Chinese novel ${ }^{1}$
}

\section{Lei Feng}

Department of Afrikaans and Dutch, Stellenbosch University, and Taiyuan University of Technology, PRC

Email: leifeng@sun.ac.za

\begin{abstract}
This article aims to review the theoretical assumptions of the phenomenon of retranslation, and to test some of these assumptions by studying the data collected from three sample chapters taken from the two complete English translations of Sanguo Yanyi - the first Chinese novel. Firstly, the three suggested denotations of the concept of 'retranslation' are identified and clarified. Secondly, the assumptions of retranslation are described, i.e. the necessity for retranslation, motives for retranslation, and the relation between the first translation and the retranslation of the same source text. Thirdly, the data from the sample chapters are analysed to test these assumptions. The general macro-structural features and some of the microstructural features of the two translations are studied and compared. Lastly, a conclusion from the findings is drawn as the verification of the assumptions of the retranslation. The hypotheses of retranslation are also briefly discussed.
\end{abstract}

Keywords: retranslation, Sanguo Yanyi, retranslation assumptions, hypotheses of retranslation, domestication, foreignisation

\section{Introduction}

Retranslation is a widespread phenomenon which has been discussed and studied by translators and Translation Studies (TS) scholars for years. This study aims firstly to review the theoretical assumptions made on retranslation, and secondly to test some of these assumptions based on the data collected from three sample chapters (and their two translations) taken from Sanguo Yanyi, the first Chinese novel.

In a broad sense within TS, the term "retranslation" may have three denotations. Traditionally, it refers to an "indirect", "intermediate", "relay" or "second-hand" translation (Shuttleworth and Cowie 1997:76). This denotation of the term refers to a procedure whereby a text is translated through a mediating source language or a language other than either the source language or the target language. Different English versions of the Bible which are not translated directly from Hebrew (the Old Testament) or Greek (the New Testament) would be a typical

\footnotetext{
${ }^{1}$ This article is based on Feng (2012).
} 
example of this denotation. In the 1920s and 1930s in China, Hans Christian Andersen's fairy tales, Henrik Ibsen's dramatic works, Miguel de Cervantes' magnum opus Don Quixote, and some works from the former Soviet Union were translated into Chinese from English or French versions; these translations might have been more widespread and accessible than the texts in their original languages. Another reason might be that the Chinese translators of these works, at that time, could only read English or French.

The second denotation can be termed a "back translation", which refers to a target-language text that is translated back into the language of the source text (ST) for the purposes of comparison and correction. A back translation is usually used for assessing the semantic range of the source-language text (Almberg 1995:925). Sometimes back translation occurs in some peculiar circumstances, such as when a translated version is published first due to the fact that the original text or manuscript was lost before it ever went to print. Years later, when the need or wish arises to publish the original text, a back translation becomes the only option. It must be noted that the back-translation text can only be secondary since its ST, which is the translation of a ST, is already second-hand material.

However, the most commonly used denotation of the term "retranslation" refers to "either the act of translating a work that has previously been translated into the same language, or the result of such an act, i.e. the retranslated text itself" (Gürçağlar 2009:233). This phenomenon is also called "new translation" or "multiple translations" (Almberg 1995:927), which refers to a text that is translated more than once into the same target language or different target languages.

The present study will focus on this last denotation of the concept, and the term "retranslation" is used specifically to refer to the new translation of the same ST into the same target language.

\section{Assumptions on retranslation}

The most frequently retranslated works are sacred texts and literary works (Brownlie 2006:146, Aaltonen 2003). Most great classics of the world have been translated more than once. Retranslation of these texts has usually been regarded by many as a positive phenomenon, as it contributes to the diversity and broadening of the available interpretations of the ST. Nonliterary retranslation, such as of scientific and technical texts, is a practice that is best avoided as it is generally viewed as redundant repetition (Gürçağlar 2009:233).

Retranslation of a book is normally conducted by a different translator at a different time. The period of time between the initial translation and the retranslation may vary from a few years to hundreds of years. Short texts, such as poems, may be retranslated more frequently than lengthy works. For instance, one of the most popular Chinese poems Jing Ye Si (lit. 'Silent Night Thinking'), which has only four lines, has at least 30 English translations ${ }^{2}$. The reason is obvious: it usually takes one less time and effort to translate a short text than it does a longer one. The same translator may also retranslate a text that $\mathrm{s} /$ he has translated before. For instance, in $1944 \mathrm{Fu}$ Lei published his Chinese translation of Honoré de Balzac's novel Le Père Goriot (1835). Six years later, Fu had a retranslation published because he was not satisfied with his first translation, which he thought was "too rigid and inflexible, not fluid and smooth enough, and the original rhythm and taste [was] lost" (Fu 1951:81).

\footnotetext{
${ }^{2}$ Feng (ed.) Handbook of Chinese English Translation (forthcoming).
} 
Some assumptions have been made on the retranslation of literary works. What follows is an attempt to describe these assumptions from the following three perspectives:

1. The necessity of retranslation, i.e. is retranslation necessary or "wasteful"?

2. Motives for retranslation, i.e. why do retranslations occur?

3. The relation between the first or initial translation and the "new" translation(s).

\subsection{The necessity of retranslation}

Though retranslation has been criticised by some scholars as being "wasteful" (Almberg 1995:926), this phenomenon still exists. In China, translation scholars have been discussing retranslation since the 1930s. Modern Chinese writer and translator Lu Xun (1881-1936) published an essay in 1935 in favour of retranslating important literary works. In his essay, entitled Multiple Retranslations are Necessary, he argued that a retranslation was necessary even if a good translation of the same work already existed, as the retranslator could benefit from the old translation and try to achieve "perfection". He even went as far as suggesting that two or more contemporary translators should commence translating the same work at the same time with full awareness of each other's on-going work, so as to encourage competition. Furthermore, he noted that language is changing all the time, so a work can deserve as many as seven or eight translations or retranslations. Another renowned literary critic, Mao Dun (18961981), was also a strong supporter of retranslation. He made comments on the two Chinese translations of Brontë's Jane Eyre, arguing that both works are good translations and, more importantly, that both also provide material or data for translation scholars or translators to study and compare different methods of translation in order to improve translation quality (Mao 1980:19). Good literary works are written in powerful language and are psychologically penetrating. Different translators, no matter the time or historical periods, first as readers of the original work, may have different interpretations of the same work (here the ST), and in their attempts to render the work in a different language, the word choice and writing style in their translations may also be different. This should be viewed as beneficial for both readers of the translations, who are offered an opportunity to choose from a variety of versions to read, and TS scholars, who will have more data (in the form of different versions of translation) to conduct their research.

The "retranslation hypothesis" was originally suggested by the French translation scholar Antoine Berman in 1990. In terms of literary retranslation, Berman argued that the translation of literary works is an "incomplete act", and only through retranslations can it strive for completion (Berman 1990:1). Berman's "completion" means the retranslation is usually "closer" to the ST. This notion was also discussed by Venuti (1995) who suggested foreignised translation be conducted rather than domesticated translation which had been dominating the industry for years. Snell-Hornby (1988:113-114) argues that literary translation is an act of communication, and any translation can rarely attain the stability of an original work. Generations later, the translation "loses its communicative function as a work of literature within a continually shifting cultural system". Then, the need to create new translations arises. This can be reflected in the Chinese translation of the $19^{\text {th }}$ century English novel Jane Eyre. The initial translation was first published in 1945, four years before the People's Republic of China was founded. The second Chinese translation only appeared in 1980, two years after China adopted the policy of opening to the outside world and in a totally different cultural system from that in 1945 when China was still a half-colonised and half-feudal society. 


\subsection{Motives for retranslation}

Works are retranslated for one or more reasons. Retranslation can be initiated by the translator, the publisher or the author of the ST, or perhaps any two of the three parties. With regard to the translator of literary works, there may be two situations where retranslation occurs: in some cases, due to lack of communication or information, the translator does not have knowledge of a pre-existing translation or, according to Venuti (2003:25), some translators may not be aware of the presence of an earlier translation. This situation is termed "passive retranslations" by Pym (1998:82).

However, in most cases, the translator is fully aware of the existing translation yet still does the retranslation, the reason usually being that $\mathrm{s} / \mathrm{he}$ is not satisfied with the pre-existing translation and wants to do it differently. Furthermore, according to Venuti (2003:30), some retranslations may originate purely from a translator's personal appreciation of a text with no other reasons. This situation is termed by Pym (1998:82) as "active retranslations", the cause of which is suggested to be "disagreements over translation strategies" in addition to a translator's personal appreciation of the original work.

With regard to the publisher, there may also be several situations where retranslation occurs, as explained by Gürçağlar (2009:235):

1. The publisher wishes to publish a different translation of a desired book (say a classic novel whose copyright has expired already) that has been translated and published by another publisher;

2. The publisher expects that a retranslation may introduce a new interpretation of the source text or address a different readership.

If a translation is very old, and the language and style become outdated, a new translation will be necessary for a contemporary readership. Berman (1990) calls this the "issue of ageing", and suggests that "while originals remain forever 'young', translations will age with the passage of time, thus giving rise to a need for new translations" (Berman 1990:1). This is true in the sense that the original work is the only version in existence, and its translations may vary in language or format. The ageing of translations and the need for new translations are also associated with "language change and the need to update the wording and terminology used in earlier translations" (Hanna 2006:194).

Some scholars also suggest that "changing social contexts and the evolution of translation norms" contribute greatly to the motives for retranslation (Brownlie 2006:150). However, in the case study that follows, the "translation norm" prevalent at the time when the initial translation was conducted (early 1900s) is not easily determined. Therefore, only the social contexts will be described in the following sections.

\subsection{The relation between the first translation and the "new" translation(s)}

Venuti (2003:25) argues that retranslations "justify themselves by establishing their difference from one or more previous versions". The tension and competition between the different translations obviously favour the new ones, though the translators of these new versions may take different approaches and use different strategies from those taken and used in pre-existing 
translations to intentionally "establish the difference". It is assumed that the differences are guided more by social or ideological premises than by linguistic or literary lack in the previous translations (Venuti 2003:25).

Berman suggests that an inherent "failure" is at its peak in the first translations which, "driven by cultural and editorial considerations, are assumed to suppress the alterity of the translated text and to feature cuts and changes that are motivated by a concern for higher levels of readability" (Gambier 1994:414). Thus, the first translations are usually domesticated or targetoriented. Gambier (1994:ix-x) notes that" $[\mathrm{t}]$ he subsequent translations, by contrast, pay more attention to the letter and style of the source text and maintain a cultural distance between the translation and its source, reflecting the singularity of the latter". Thus retranslations tend to be source-oriented or foreignised ones. However, this is not always the case. One exception is the Chinese translations of the Russian novel Razgrom ('The Rout'). The initial translation by Lu Xun in 1935 was a typical foreignised one, as he intentionally used "Europeanized Chinese" and caused heated debates among writers and translators (Chan 2004:151). Later Chinese translations of the same novel, six versions in total by six different Chinese publishers ${ }^{3}$ up to the year 2013, tended to be more domesticated than the initial translation.

The assumptions from the above-mentioned perspectives can be summarised as follows:

1. In terms of necessity, retranslation of literary works is not only necessary but also important, as retranslations add value to the original work (ST).

2. In terms of motives, changing social contexts play an important role, and both the retranslator and the publisher intend to establish the difference from the preexisting translations.

3. In terms of the relationships between the initial translation and the retranslation, the former tends to be more target-oriented and more likely to take a domesticating approach, while the latter tends to take a foreignising approach. These differences are mainly guided by social or ideological premises.

In the next section, these assumptions will be tested through their application to the data.

\section{The case study}

Two English translations of the Chinese novel, Sanguo Yanyi, will be studied to test the abovementioned assumptions on retranslation. Due to the great length and extensiveness of the ST, which contains 120 chapters, three chapters are selected as foci of the analysis, especially where data are analysed on a micro-structural level. These three chapters are Chapter 1, Chapter 60 and Chapter 120. The reasons for choosing these three chapters will be detailed in section 3.3.

\subsection{The source text and the translations}

Sanguo Yanyi is the first full-length novel with clear chapter divisions to appear in China. This epic describes the political and military contention over a period of approximately 100 years (168-265 AD) among the rival power groups Wei, Shu and Wu, headed by Cao Cao, Liu Bei and Sun Quan, respectively. The three groups bid for control of the Chinese empire during the

\footnotetext{
${ }^{3}$ See http://book.douban.com/doulist/1704817/ (Accessed 19 April 2014).
} 
Three Kingdoms period, one of the most tumultuous and fascinating periods in Chinese history. The authorship of Sanguo Yanyi has been traditionally attributed to Luo Guanzhong (c.13001400) whose life and works are still largely unknown. The Chinese novel that originated from story-telling had in most cases been a collaborative work in its initial stage of development, and the author(s) was/were largely neglected.

Since its publication about 600 years ago, Sanguo Yanyi has arguably been considered the most influential novel on Chinese society. There have been many translations and retranslations of selected chapters of the novel, but, based on the author's investigation, there are only two complete English translations in circulation. The current study is based on two translations of Sanguo Yanyi, namely Brewitt-Taylor's (2002) translation entitled Romance of the Three Kingdoms, and Roberts' (1994) translation entitled Three Kingdoms: A Historical Novel.

Brewitt-Taylor's translation was first published by Kelly \& Walsh Limited in Shanghai in 1925 as two hardcover volumes. In 1929, the text was reprinted by the same publisher as a popular edition to enable more readers to afford a copy. Thereafter the translation was reprinted in the US by the Charles E. Tuttle Company in Rutland, Vermont, and simultaneously in Tokyo in 1959. Brewitt-Taylor's translation was the first full English translation of this novel.

Charlie Henry Brewitt-Taylor (1857-1938) was an Englishman who went to China in his twenties and worked as an officer for the Imperial Chinese Maritime Customs in a number of cities. He spent most of his adult life in China. In addition to a successful career as a customs official, he also achieved distinction as a scholar. In this study, Charles Henry Brewitt-Taylor will be abbreviated as "B-T" and his translation will be abbreviated as "T1".

Moss Roberts was born in New York and is a Professor of Chinese at New York University. He has also translated a number of other books from Chinese into English, in addition to Sanguo Yanyi, on which he is one of the few authorities outside China. Roberts' (1994) translation of Sanguo Yanyi, abbreviated in this article as "T2", is the latest complete English translation.

\subsection{The motives for retranslation}

As discussed in section 2.2, motives for retranslation can be analysed with regard to both the translator and the publisher. First, the motives for the initial translation of Sanguo Yanyi (i.e. those of B-T) will be briefly discussed.

B-T's translation is the initial translation which was first published in 1925. The motives for the initial translation seemed, in the first place, to be the translator's personal appreciation of the ST. B-T did receive encouragement from some scholars of his time, but whether he received any support from the publisher is not clear. Translating such an extensive work single-handedly is by no means an easy task, and it took B-T about 10 years to complete the project (Cannon 2009:155). The first print of the translation was "especially prepared for the use and education of the Chinese people" (Cannon 2009:154). The translator and publisher at that time intended to address a Chinese readership who wished to learn English by reading English translations of Chinese classics. However, the first print was a relatively expensive hardcover copy which could only be afforded by English-speaking people working and/or living in China who had an interest in exploring Chinese literature or history, and a small number of Chinese readers who wished to improve their English. It should be noted that the target readership that the 2002 
reprint of this translation aims to address has changed; judging from the introduction and the preface of this edition, the publisher's target reader is the general Western reader who wants to learn about China.

For Roberts, it can be deduced that there must have been some strong motives to encourage him, as the retranslator, to complete this translation project. In the acknowledgements, he briefly mentions the factors which contributed to his completion of the project. He studied Chinese at university and became interested in sinology. Later on he taught Chinese and philosophy to American students. In 1976, he had an abridged translation of Sanguo Yanyi published by Pantheon Books for the purpose of teaching Chinese culture to Americans. Having realised the limitations of the abridged version, he hoped that one day he would have the opportunity to translate the entire text. He got the opportunity in 1982 when Beijing's Foreign Languages Press made him the offer to translate the whole novel. At the invitation of the publisher, he spent one year (1983-1984) in Beijing focusing on the translation. He was granted a fellowship by the National Endowment for the Humanities which enabled him to devote 15 months (1985-1986) purely to his translation. A number of scholars from China and the US also offered him academic support. In 1994, the translation was completed and published jointly by Foreign Languages Press in Beijing and the University of California Press. Foreign Languages Press is a publishing house which aims to promote Chinese culture in foreign languages. The initial purpose of this retranslation thus seemed to be to address a readership outside China who is interested in Chinese studies. This version was also reprinted several times to meet the needs of Chinese learners of English. This is similar to the function of the second print of T1, a popular and relatively cheap edition to meet the needs of more Chinese learners of English.

B-T's translation must have been available at the time when Roberts was teaching Chinese in the US. Roberts (1994) mentioned in the acknowledgements of his complete translation that he had read B-T's translation:

A word of recognition is also due to C.H. Brewitt-Taylor, whose 1925 translation of Three Kingdoms I read long before gathering enough Chinese to confront the original.

Roberts did not use B-T's translation for his students; instead, he first translated some chapters himself, which then led to the publication of the abridged version. This shows that the readership this retranslation of the novel is intended to address is that of Western learners of Chinese.

In this case, it is the combination of the wishes of both Roberts and the publishers that made the retranslation possible. However, the major driving force behind the completion of the retranslation must have been the publishers. Without their support, especially financially, Roberts would not have completed the translation. Even if he did eventually translate the novel without the support of the publishers, we can assume it would have taken him more years to finish the project.

From the publisher to the readership, from an old, semi-colonised and semi-feudal China to a new, independent and opened-up China, the social contexts had obviously experienced great changes during the period of time when Roberts did the retranslation (the 1980s to the 1990s). In the time of the first English translation by B-T, the ST Sanguo Yanyi was a very popular 
novel among Chinese readers. Influential as it was, however, the novel was not considered part of important and serious texts that normally included poetry, prose and philosophical writings. B-T attempted to promote the status of popular Chinese literature in the English-speaking world. In the 1980s and 1990s, when Roberts's retranslation was conducted and published, the status of the novel was already promoted as one of the literary genres worthy of serious study. Therefore, Roberts received more support for the work.

\subsection{A comparison between the two translations from a structural point of view}

In this section, a comparison will be made to describe the differences and similarities between the initial translation by B-T, and the retranslation by Roberts. Examples and tables are provided to illustrate the findings. The reasons for the differences which arose will be investigated to verify the relevant assumptions.

As previously mentioned, for the purposes of this study, three chapters (Chapters 1, 60 and 120) and their corresponding translations were selected as the foci of the analysis. The length and extensiveness of these chapters were considered before they were selected for analysis. The three selected chapters total 46.5 pages (excluding endnotes; 53 pages including endnotes).

In consideration of the plot of the novel, the first and the last chapters are important since they reflect how the Han Empire was divided at its end into three kingdoms, and how the country was united again under the Empire of Jin. In the first chapter, the four major characters of the novel, Cao Cao, Liu Bei, Guan Yu and Zhang Fei, are introduced. The last chapter recounts how the new Jin Empire defeats the Kingdom of $\mathrm{Wu}$ and captures its king. The first and last chapters were therefore selected because of their importance in the novel, as well as their richness of cultural elements such as official ranks, reign-titles, allusions, idioms, metaphors, etc. Furthermore, there are many proper names and culture-specific elements in these two chapters.

Other factors, such as those reflecting strategies of dealing with culture-related references and degrees of consistency, were also taken into consideration in the selection of chapters as the foci of the analysis. Chapter 60 was chosen for three reasons: firstly, this chapter is right in the middle of the book, and by studying and comparing the relevant items in this chapter and the other two chapters, the consistency of the translators' use of strategies or adoption of approaches can be determined. Secondly, this chapter contains numerous dialogues, which is the key method used to portray characters in traditional Chinese novels. These dialogues or direct speeches provide material for analysis regarding the strategies adopted by the two translators. Finally, in terms of the plot, Chapter 60 includes some important events which are crucial to Liu Bei's successful invasion of the west province, which is later to become the base of the Kingdom of Shu.

The method used to compare the two translations is based on the Synthetic Scheme for Translation Description (see Table 1) suggested by Lambert and van Gorp (1985). 
Table 1. Lambert and van Gorp's (1985) Synthetic Scheme for Translation Description

\begin{tabular}{|l|l|}
\hline \multicolumn{1}{|c|}{ Category } & \multicolumn{1}{c|}{ Aspects } \\
\hline Preliminary data & information on title page, paratexts, general strategy \\
\hline Macro-level structures & the division of the text, titles and presentation of the chapters \\
\hline Micro-level structures & translation shifts: lexical, grammatical patterns, word use \\
\hline Systemic context & intertextual relations, norms \\
\hline
\end{tabular}

In the following sections, the original category has been changed a bit by combining the preliminary data and the macro-level structures so that only the macro-structural and microstructural features of the translations will be compared.

\subsubsection{Macro-structural features}

In terms of the macro-level structures, the aspects to be compared and analysed include: the title, title page and paratexts; general strategy; division of the text; titles of chapters; and the relation between types of narrative, dialogue, description.

\subsubsection{The title, title page and paratexts}

The title of T1 is Romance of the Three Kingdoms. In T2 Three Kingdoms is adopted as the main title, primarily in order to differentiate it from the previous translation. The subtitle $A$ Historical Novel is provided to differentiate it from Records of the Three Kingdoms, which is believed to be the main source from which the original novel drew material.

T1 appears as two paperback volumes. The volume number is printed on both the front cover and on the title page inside the book. On the cover page, the title of T1, Romance of the Three Kingdoms, is printed in large letters in a bilingual format. Next to this on the left is the original Chinese title in traditional Chinese characters printed in a vertical direction, which had been the customary manner of printing Chinese texts before 1919. At the bottom, the names of the author, translator, and writer of the introduction are printed in smaller letters. The name of the publisher is printed at the bottom on the left side in very small letters, indicating it as a "classic". The same information, except for the Chinese title, is repeated on the second page of the book.

T2 is a hardcover in three volumes. Each of the three volumes has a book jacket. The translated title, Three Kingdoms, is printed on the front cover together with a picture of the main characters. The original title in Chinese is printed on the front page of the hardcover, hidden underneath the book jacket. The title and the subtitle, volume number and the names of the publishers appear on the spine. On the flaps of the book jacket the following information is contained: the full title; a brief introduction to the author, the translator, the person who wrote the foreword, the novel and its current translation. On the second page, inside the book, the full title, author's name, translator's name and full names of the publishers are printed.

On the back cover of $\mathrm{T} 1$ is a brief comment on the novel which reads "One of the greatest and best-loved works of popular literature", as well as a short introduction to the novel itself. There is an introduction written by Robert E. Hegel and a short note from the translator. The few notes are either incorporated into the text or placed in brackets following the words. 
In T2, extensive information is provided to help the Western reader understand the translation. The information includes: the translator's acknowledgements; a foreword; a long commentary or afterword; a full set of notes which are grouped by chapter (but all notes are placed at the end of the last volume); a list of principal characters; a dozen illustrations; a list of maps; a chronology of main events; a list of titles, terms and offices; and a short introduction to the translator.

\subsubsection{General strategy}

Both translations are based on the same version of the ST and both are complete translations, though more omissions are identified in T1 than in T2. Two notable omissions found in the selected chapters from T1 include a poem at the beginning of the book, and a paragraph at the end of the last chapter stating the death years of the kings.

The word count includes all the words in both the selected texts and the notes to these texts. Both translators use more or less the same number of words. For Chapters 1 and 120, Roberts uses about 800 more words (as notes) to explain background knowledge and culture-specific references, but uses fewer words than B-T to translate Chapter 60 (see Table 2).

Table 2. Number of words in the selected source texts and the target texts

\begin{tabular}{|cccc|}
\hline & Chapter 1 & Chapter 60 & Chapter 120 \\
\hline ST & 4639 & 7303 & 5529 \\
\hline T1 & 4667 & 7204 & 6169 \\
\hline T2 & 5544 & 7160 & 6924 \\
\hline
\end{tabular}

\subsubsection{Division of the text}

The ST is not divided into many paragraphs, and many dialogues - usually short and brief - are packed into one paragraph. This format of the ST is changed to a large extent in both translations. In T1, the format of the ST is treated more freely: a paragraph is split into many smaller paragraphs, and many of the single-sentence dialogues are treated as separate paragraphs (see Table 3). T2 remains relatively closer to the ST than does T1. In this respect, T1 seems to have taken a domesticating approach while T2 can be considered to have taken a more foreignising approach. This confirms the third assumption discussed in section 2.3.

Table 3. Number of paragraphs in the selected source texts and the target texts

\begin{tabular}{|lcll|}
\hline & Chapter $\mathbf{1}$ & Chapter $\mathbf{6 0}$ & Chapter 120 \\
\hline ST & 12 & 20 & 22 \\
\hline T1 & 76 & 176 & 140 \\
\hline T2 & 43 & 49 & 55 \\
\hline
\end{tabular}

\subsubsection{Titles of chapters}

The title of each chapter in the ST is a neat couplet - an attempted summary of the corresponding chapter. In terms of the format, capital letters and Roman numerals are used in T1. This achieves an element of antiquity, attempting to bring the translation closer to the 
original which was written about 600 years ago. In T2, the titles are printed in a standard, contemporary way, intending to address the contemporary English readership; this seems to be an attempt at domesticating the text. On the whole, T2 seems to be more foreignised than T1 but with regard to some elements, such as chapter titles, it seems that T2 is more domesticated. When translating these titles, it appears that both translators attempted to keep the original "flavour" of the ST by taking a foreignising approach (see Table 4), but neither has achieved the same structural effect as that found in the ST, which is a neat, well-designed couplet unique to the Chinese language.

Table 4. Translation of chapter titles

\begin{tabular}{|c|l|}
\hline ST & 第一回 宴桃园豪杰三结义 斩黄巾英雄首立功 \\
\hline T1 & CHAPTER I \\
\hline & $\begin{array}{l}\text { FEAST IN THE GARDEN OF PEACHES: BROTHERHOOD } \\
\text { SWORN }\end{array}$ \\
\hline T2 & SLAUGHTER OF REBELS: THE BROTHERS HEROES \\
\hline & Chapter 1 \\
\hline $\begin{array}{c}\text { Direct } \\
\text { translations: }\end{array}$ & Three Bold Spirits Plight Mutual Faith in the Peach Garden \\
\hline & Feast [in] the Peach Garden Heroes Three Swear Brotherhood \\
\hline & Slaughter the Yellow Scarves the Heroes Wins Top Honours \\
\hline
\end{tabular}

\subsubsection{Relation between types of narrative, dialogue and description}

In most cases, both T1 and T2 deal with the narratives, dialogues and descriptions as they appear in the ST. However, in terms of effect, as illustrated in Example 1, there seems to be little difference between the two translations.

\section{Example 1 (Chapter 1):}

ST: 玄德曰 : “此天佑我也!”三人出庄迎接。

T1: “Thus does Heaven help us," said Yuan-te and the three brothers went forth to welcome the merchants.

T2: "This must mean that the Heaven is with us," said Xuande, as the three brothers went forth to greet the men.

(Direct translation: 'Xuande said: "This must mean the Heaven is helping us!" [as] the three brothers went out of the manor to meet the [men]')

T1 uses narratives to translate dialogues and monologues more often than $\mathrm{T} 2$, as illustrated in Example 2. This example indicates that $\mathrm{T} 2$ is more source-oriented, at least in terms of sentence structure.

\section{Example 2 (Chapter 60):}

ST: 璋曰：“公所谋, 深于吾有益。”次日, 上马出榆桥门。

T1: So spoken Chang Sung and the Prefect replied that he knew the plan was for his advantage. Whereupon he mounted his horse to ride out to Elm Tree Bridge. 
T2: "Your planning," Liu Zhang said, "serves my interest profoundly.” The next day Liu Zhang rode to Elm Bridge Gate.

(Direct translation: '[Liu] Zhang said: "Your planning serves my interest profoundly." The following day, [Liu Zhang] mounted horse to ride out to Elm Bridge Gate.')

It must be pointed out that most of the dialogues or monologues which were transformed into narratives in $\mathrm{T} 1$ are not the key dialogues which reflect the personalities of the characters. However, these examples still indicate that, in terms of format, T1 is less faithful to the ST than $\mathrm{T} 2$.

\subsubsection{Micro-structural features}

The micro-structural aspects to be compared in this section include the selection of words; omissions and explications; translation of the number of troops; translation of proper names, units of measurement, titles of emperors, and ranks of officers or officials.

\subsubsection{Vocabulary}

The ST was written in the $14^{\text {th }}$ century, hence the vocabulary is largely archaic. In T1, old words are used from time to time, and more modern English words are used in T2. In Example 3, the dated phrase "ere long" is used in T1 whereas T2 uses "soon". The use of archaic words in T1 indicates that, in terms of vocabulary, T1 is closer to the ST than T2. The use of more modern English words in T2 verifies the assumption that "the ageing of translations and the need for new translations are also associated with 'language change and the need to update the wording and terminology used in earlier translations"” (Hanna 2006:194. cf. Section 2.2).

Example 3 (Chapter 120):

ST: 华覈出朝叹曰：“可惜锦绣江山, 不久属于他人矣！”

T1: "It is pitiful," said he, "Ere long our beautiful country will pass to another."

T2: Hua He left the court and uttered a deep sigh. "Alas," he said, "These hills and streams that nature made so lovely are soon to pass to another's hands."

(Direct translation: 'Hua He left the court and sighed: "Pitiful that such lovely and beautiful rivers and mountains will soon belong to others".')

\subsubsection{Omissions and explications}

In $\mathrm{T} 1$, lists of proper names and places are not always fully translated, however in $\mathrm{T} 2$ these lists are all translated word-for-word (see Example 4).

\section{Example 4 (Chapter 1):}

ST: 青、幽、徐、冀、荆、扬、充、豫八州之人，家家侍奉大贤良师张角名字。

T1: With the growth of the number of his supporters grew also the ambition of the "Wise and Good." He dreamed of empire.

T2: Great and Worthy Teacher, was hailed throughout the eight provinces of the realm - Qingzhou, Xuzhou, Jizhou, Jingzhou, Yangzhou, Yanzhou, and Yuzhou. 
(Direct translation: 'Every household from Qingzhou, Xuzhou, Jizhou, Jingzhou, Yangzhou, Yanzhou, and Yuzhou enshrined the Great and Worthy Teacher Zhang Jiao.')

These proper names in translation actually do not make much sense to most of the target readers. This indicates that a more foreignising approach is taken in T2, while T1 is obviously a more domesticated translation.

Berman (2000:289) notes that, in a translation, "[t]he explicitation can be the manifestation of something that is not apparent, but concealed or repressed, in the original". In both T1 and T2, explicitations are made to introduce background knowledge or cultural-specific items (see Example 5). In T1, the extra background information is incorporated into the text, but in $\mathrm{T} 2$ the provision of footnotes is the major method utilised to provide this information. The latter reflects the translator's intention to make the translation a scholarly work for study instead of just a popular novel to read for fun. With the use of footnotes, T2 also becomes much more visible as a translation.

Example 5 (Chapter 1):

ST: 光和元年, 此难鸡化雄。

T1: Another evil omen was recorded ten years later, when the reign-title was changed: certain hens suddenly developed male characteristics, a miracle which could only refer to the effeminate eunuchs meddling in affairs of State.

T2: In the first year of Radiant Harmony (Guang He) hens were transformed into roosters. ${ }^{4}$

(Direct translation: 'First year Guang He, hens [were] transformed into roosters.')

The endnote as extra background information appears in T2 to show the translator's attempt at keeping his translation as close as possible to the ST, which could be considered as the adoption of a more foreignising approach. Removing the explanations from the body of the text enables the reader, who does not seek extra information, to read more smoothly. For those who need or want to explore further, the note provided by the translator can be useful.

\subsubsection{Translation of the numbers of troops}

While T2 treats the numbers of troops very faithfully, T1 uses a variety of ways to deal with them. Words used in T1 to translate the numbers include "huge", "goodly", "large", "legion", "company", "score", etc. In some cases (about 20\% according to the data of the three chapters), numbers are ignored and omitted, where B-T might have regarded them as unimportant. In fact, in the ST, which is a novel instead of a historical record, not all of these numbers are precise figures, so it is not improper to translate them in a flexible way (see Table 5). Again, this indicates that the two translators used different strategies, namely one of a more liberal nature in $\mathrm{T} 1$, and one of a more literal nature in $\mathrm{T} 2$.

\footnotetext{
${ }^{4}$ The endnote provided in $\mathrm{T} 2$ is omitted here.
} 
Table 5. Numbers of troops

\begin{tabular}{|c|c|l|l|}
\hline Chapter & \multicolumn{1}{|c|}{ ST } & \multicolumn{1}{|c|}{ T1 } & \multicolumn{1}{c|}{ T2 } \\
\hline $\mathbf{1}$ & 兵五万 & a huge army & fifty thousand men \\
\hline $\mathbf{1}$ & 一千军 & a goodly party & one thousand men \\
\hline $\mathbf{6 0}$ & 五万 & five legions & Fifty thousand \\
\hline $\mathbf{6 0}$ & 三万人马 & a great company & thirty thousand soldiers \\
\hline $\mathbf{1 2 0}$ & 引兵十万 & - & lead a force of one hundred thousand \\
\hline $\mathbf{1 2 0}$ & 八百军 & the men & eight hundred sailors \\
\hline
\end{tabular}

\subsubsection{Translation of proper names}

In $\mathrm{T} 1$, the Wade-Giles system is used to transcribe proper names. Wade-Giles was the main system of transcription of proper names and cultural items from the Chinese language in the English-speaking world for most of the $20^{\text {th }}$ century. Specifically, the Wade-Giles system is the representation of the unaspirated-aspirated stop consonant pairs using apostrophes, for example $p, p^{\prime}, t, t^{\prime}, k, k^{\prime}, c h, c h^{\prime}{ }^{5}$

In T2, however, Pinyin is used to transcribe proper names. This is a Romanised system functioning to annotate standard Chinese pronunciation with Roman letters. The system was adopted in 1979 by the International Organization for Standardization (ISO) as the standard Romanisation for modern Chinese (ISO-7098:1991). Roberts' translation received support from the Beijing-based publisher Foreign Languages Press, so the use of Pinyin would have been one of their requirements. Table 6 shows that T1 used the old phonetic system while T2 used the new system. In this case, the changing social contexts clearly play an important role, as stated in the second assumption in section 2 .

Table 6. Personal names

\begin{tabular}{|l|l|l|l|}
\hline & Surname & Given name & Courtesy name \\
\hline ST & 刘 & 备 & 玄德 \\
\hline T1 & Liu & Pei & Yuan-te \\
\hline T2 & Liu & Bei & Xuande \\
\hline
\end{tabular}

For a person who speaks a European language, it might be easier to spell some of the Chinese sounds by using the Wade-Giles system. However, the sounds represented in Pinyin can be pronounced in a more correct way, i.e. the names in Table 6 are spelled closer to their Chinese sounds when Pinyin is employed, as in T2.

\footnotetext{
${ }^{5}$ See http://www.newworldencyclopedia.org/entry/Wade-Giles (Accessed 29 April 2014).
} 


\subsubsection{Units of measurement}

In both translations, all the units in the selected texts are translated using either transcription (两 to liang, 里 to li) or assimilation (两 to ounce, 斗 to bushel). However, footnotes for some of the translations are provided in T2 (see Table 7), which reflects the translator's attempt to make it a scholarly work instead of simply a novel to entertain readers. This treatment in T2 also makes the text more accessible to the target reader. The foreignising approach taken in T2 is obvious, which proves the third assumption in section 2 to be true.

Table 7 Units of measurement

\begin{tabular}{|l|c|l|l|l|l|}
\hline & ST & \multicolumn{1}{|c|}{ Chapter } & \multicolumn{1}{|c|}{ T1 } & \multicolumn{1}{c|}{ T2 } & \\
\hline Weight & 两 & 1,60 & liang & ounce/tael/liang & T2 gives notes \\
\hline Weight & 斤 & 1 & catty & jin & T2 gives notes \\
\hline Length & 丈 & 1 & ten-foot & ten-span & T2 gives notes \\
\hline Length & 里 & $1,60,120$ & $l i$ & $l i$ & \\
\hline Volume & 斗 & 60,120 & bushel & bushelful/gallon & \\
\hline Area & $\begin{array}{l}\text { 八百 } \\
\text { 余顷 }\end{array}$ & 120 & extensive area & $\begin{array}{l}\text { some five thousand } \\
\text { hectares of land }\end{array}$ & \\
\hline
\end{tabular}

\subsubsection{Reign-titles}

In T1, the reign-titles are largely ignored, however, in T2, they are explicated through both transcription and word-for-word translation of meanings. In addition, in the last chapter of T2, the corresponding years based on the Gregorian calendar of these reign-titles are also provided as a reference for the reader (see Table 8).

Table 8. Reign-titles

\begin{tabular}{|c|l|l|l|}
\hline ST & Chapter & \multicolumn{1}{c|}{ T1 } & \multicolumn{1}{c|}{ T2 } \\
\hline 建宁 & 1 & Chien-Ning & Established Calm (Jian Ning) \\
\hline 光和 & 1 & - & Radiant Harmony (Guang He) \\
\hline 中平 & 1 & - & Central Stability (Zhong Ping) \\
\hline 甘露 & 120 & Kan-lu & Gan Lu, “Sweet Dew," year 1 (A.D. 265) \\
\hline 宝鼎 & 120 & Pao-Ting & Bao Ding, "Precious Tripod,” year 1. (A.D. 266) \\
\hline 建衡 & 120 & - & Jian Heng, "Established Balance” (A.D. 269-71) \\
\hline
\end{tabular}

In terms of a title or an office that a person held or was appointed to, in T1, only about half of these titles are translated and the other half are omitted from the translation. Translation 
strategies used to translate these titles are varied and inconsistent. Sometimes transcription is used, for example 校尉 is transcribed as Hsio-yu; but assimilation is used on more occasions, like “General of Cavalry” for 骠骑将军.

All 46 titles in the selected chapters are translated in T2. The translation of these titles, all translated by using assimilation as a strategy, is consistent throughout. A minor issue is that capital letters are not used for a few fixed titles, such as "minister of the interior" and "minister of works".

This comparison reflects that T1 mainly adopted a domesticating approach by omitting or downplaying some of the reign-titles, whereas T2 adopted both a foreignising approach (e.g. by providing transliteration and explanatory notes) and a domesticating approach (e.g. by elaborating on these titles and meaning renditions).

\section{Conclusion}

In sections 3.1 and 3.2, both macro and micro features of the selected chapters of Sanguo Yanyi and their translations have been discussed. The findings from the comparison of the two translations are summarised in Table 9:

Table 9. A comparison of the features of the two translations

\begin{tabular}{|c|l|}
\hline Version & \multicolumn{1}{c|}{ Features } \\
\hline $\mathrm{T} 1$ & $\begin{array}{l}\text { more domesticated translation } \\
\text { reads like a novel } \\
\text { relatively incomplete and inconsistent } \\
\text { sounds archaic }\end{array}$ \\
\hline $\mathrm{T} 2$ & $\begin{array}{l}\text { more foreignised translation } \\
\text { reads like a scholarly work } \\
\text { complete and consistent } \\
\text { addresses contemporary readership }\end{array}$ \\
\hline
\end{tabular}

From the concluded features of the two translations, it can be seen that the retranslation is both necessary and important, thus the first assumption summarised in section 2.3 is proved to be true.

In terms of motives for retranslation, summarised in the second assumption in section 2.3, changing social contexts have played an important role in the decision-making of both the retranslator and the publisher who attempted to bring out something different. The initial translation was motivated by the translator's personal appreciation of the work, and the retranslation was motivated by both the publisher(s) and the translator's personal appreciation of the work (cf. section 3.2).

Through the discussions in section 3, and the summarised features listed in Table 9 above, it seems obvious that $\mathrm{T} 1$ is generally a domesticated translation and the retranslation, $\mathrm{T} 2$, appears to be a foreignised translation. However, the adoption of a domesticating approach is also observed from time to time in T2, e.g. in certain elaborations and the explanatory notes. 
Different social premises are suggested to have played the primary role in the different approaches taken by the two translators.

In conclusion, based on the analysis of the examples from the selected chapters in this case study, the three assumptions or hypotheses regarding retranslation have been verified as true, though not all items compared (cf. titles of chapters and vocabulary) clearly support this stand.

\section{References}

Aaltonen, S. 2003. Retranslation in the Finnish theatre. Cadernos de Tradução: Tradução, retradução e adaptação 1(11): 141-159.

Almberg, S.P.E. 1995. Retranslation. In S.W. Chan and D.E. Pollard (eds.) An encyclopedia of translation Chinese-English English-Chinese. Hong Kong: The Chinese University Press. pp. 925-929.

Berman, A. 1990. La retraduction comme espace de traduction. Palimpsestes 4: 1-7.

Berman, A. 2000. Translation and the trial of the foreign. In L. Venuti (ed.) The translation studies reader. London and New York: Routledge. pp. 284-297.

Brewitt-Taylor, H.C. 2002. Romance of the Three Kingdoms. Singapore: Tuttle Publishing.

Brownlie, S. 2006. Narrative theory and retranslation theory. Across Languages and Cultures 7(2): $140-170$.

Cannon, I.C. 2009. Public success, private sorrow. Hong Kong: Hong Kong University Press.

Chan, L.T. (ed.) 2004. Twentieth-century Chinese translation theory: Modes, issues and debates. Amsterdam: John Benjamins.

Feng, L. 2012. Two English translations of the Chinese epic novel Sanguo Yanyi: A descriptive and functionalist study. $\mathrm{PhD}$ dissertation. University of Stellenbosch.

Feng, L. (ed.) Forthcoming. Handbook of Chinese English translation.

Fu, L. 1951. Preface to the retranslated Chinese version of Le Père Goriot. In Fanyi yanjiu lunwenji (1949-1983) (Selected papers on translation studies). 1984. Beijing: Foreign Language Teaching and Research Press. pp. 80-81.

Gambier, Y. 1994. La retraduction, retour et détour. Meta 39(3): 413-417.

Gürçağlar, Ş.T. 2009. Retranslation. In M. Baker and G. Saldana (eds.) Routledge encyclopedia of translation studies. pp. 232-235. 
Hanna, S.F. 2006. Towards a sociology of drama translation: A Bourdieusian perspective on translations of Shakespeare's great tragedies in Egypt. Unpublished $\mathrm{PhD}$ dissertation. University of Manchester, Centre for Translation and Intercultural Studies.

Lambert, J. and H. van Gorp. 1985. On describing translations. In T. Hermans (ed.) The manipulation of literature: Studies in literary translation. Beckenham: Croom Helm. pp. 4253.

Lu, X. 1935. Multiple retranslations are necessary. In Fanyi yanjiu lunwenji (1894-1948) ('Selected papers on translation studies'). 1984. Beijing: Foreign Language Teaching and Research Press. pp. 242-243.

Mao, D. 1980. Preface to Selected Translations of Mao Dun. In Fanyi yanjiu lunwenji (19491983) ('Selected papers on translation studies'). 1984. Beijing: Foreign Language Teaching and Research Press. pp. 17-19.

Pym, A. 1998. Method in translation history. Manchester: St. Jerome Publishing.

Roberts, M. 1994. Three kingdoms: A historical novel. Beijing \& Berkeley, Los Angeles: Foreign Languages Press and University of California Press.

Shuttleworth, M. and M. Cowie. 1997. Dictionary of translation studies. Manchester: St. Jerome Publishing. pp. 139-140.

Snell-Hornby, M. 1988. Translation studies: An integrated approach. Amsterdam/Philadelphia: John Benjamins Publishing Company. pp. 113-114.

Venuti, L. 1995. The translator's invisibility: A history of translation. London and New York: Routledge.

Venuti, L. 2003. Retranslations: The creation of value. Bucknell Review 47(1): 25-39. 